\title{
In Vivo Labeling of Parvalbumin-Positive Interneurons and Analysis of Electrical Coupling in Identified Neurons
}

\author{
Axel H. Meyer, ${ }^{1}$ István Katona, ${ }^{1}$ Maria Blatow, ${ }^{1}$ Andrei Rozov, ${ }^{2}$ and Hannah Monyer ${ }^{1}$ \\ ${ }^{1}$ Department of Clinical Neurobiology, Interdisciplinary Center for Neurosciences, University of Heidelberg, 69120 \\ Heidelberg, Germany, and 2Department of Experimental Neurophysiology, Faculty of Earth and Life Science, Vrije \\ University Amsterdam, De Boelelaan 10871081 HV Amsterdam, The Netherlands
}

\begin{abstract}
GABAergic interneurons can pace the activity of principal cells and are thus critically involved in the generation of oscillatory and synchronous network activity. The specific role of various GABAergic subpopulations, however, has remained elusive. This is in part attributable to the scarcity of certain GABAergic neurons and the difficulty of identifying them in slices obtained from brain regions in which anatomical structures are not readily recognizable in the live preparation. To facilitate the functional analysis of GABAergic interneurons, we generated transgenic mice in which the enhanced green fluorescent protein (EGFP) was specifically expressed in parvalbumin-positive neurons. The high fidelity of expression obtained using bacterial artificial chromosome transgenes resulted in EGFP-labeled neurons in nearly all brain regions known to contain parvalbumin-expressing neurons. Immunocytochemical analysis showed that EGFP expression was primarily restricted to parvalbumin-positive cells. In addition to cell body labeling, EGFP expression was high enough in many neurons to
\end{abstract}

GABAergic interneurons in the forebrain, although only a small part of the total neuronal population, are of pivotal importance for the coordinated activity of large neuronal ensembles. Single inhibitory neurons innervate hundreds of principal neurons (Halasy et al., 1996) and thus are well suited to synchronize cortical network activity (Galarreta et al., 1999; Gibson et al., 1999) in different frequency bands (Cobb et al., 1995; Ylinen et al., 1995; Tamas et al., 2000; Szabadics et al., 2001). In the mammalian brain, large-scale synchronous and oscillatory activity in the gamma $(30-80 \mathrm{~Hz})$ and fast $(200 \mathrm{~Hz})$ range have been identified by electrophysiological studies (Singer and Gray, 1995; Ylinen et al., 1995; Traub et al., 1998). It is thought that this oscillatory activity plays an important role in cognition, memory formation, and other higher nervous system functions (Gray et al., 1989; Miltner et al., 1999; Rodriguez et al., 1999). Electrophysiological studies in hippocampal (Whittington et al., 1995; Ylinen et al., 1995; Traub et al., 1996; Hormuzdi et al., 2001) and neocortical (Galarreta et al., 1999; Gibson et al., 1999; Beierlein

Received March 7, 2002; revised June 3, 2002; accepted June 7, 2002.

This work was supported in part by Novartis Pharma AG and the Schilling Foundation (H.M.). I.K. was a recipient of a European Molecular Biology Organization long-term fellowship. M.B. was supported by the Graduate Program of Molecular and Cellular Neurobiology of the University of Heidelberg. We thank $\mathrm{X}$. W. Yang and N. Heintz for reagents for BAC modification, P. H. Seeburg and W. Wisden for critical reading of this manuscript, $\mathrm{N}$. Shahani for help with confocal microscopy, and E. Fuchs and H. and H. Meyer for help with the mice.

Correspondence should be addressed to Dr. Hannah Monyer, Department of Clinical Neurobiology, University Hospital for Neurology, Im Neuenheimer Feld 364, Heidelberg, Germany. E-mail: monyer@urz.uni-hd.de.

Copyright $\odot 2002$ Society for Neuroscience $0270-6474 / 02 / 227055-10 \$ 15.00 / 0$ enable the visualization of dendritic structures. With the help of these mice, we investigated the presence of electrical coupling between parvalbumin-positive cells in brain slices obtained from young and adult animals. In dentate gyrus basket cells, electrical coupling was found in slices from young [postnatal day 14 (P14)] and adult (P28 and P42) animals, but both strength and incidence of coupling decreased during development. However, electrical coupling between parvalbumin-positive multipolar cells in layer II/III of the neocortex remains unaltered during development. Yet another developmental profile of electrical coupling was found between layer II/III parvalbumin-positive cells and excitatory principal cells. Between these neurons, electrical coupling was found at P14 but not at P28. The results indicate that the presence and strength of electrical coupling is developmentally regulated with respect to brain area and cell type.

Key words: interneuron; GABA; parvalbumin; gap junction; EGFP; BAC

et al., 2000; Tamas et al., 2000; Deans et al., 2001) slices suggest that networks of GABAergic interneurons, connected via chemical and/or electrical synapses, are critically involved in the generation of these rhythmic activities.

GABAergic interneurons do not represent a homogeneous population but can be divided into a number of different subtypes. Several criteria have been used to characterize subpopulations of GABAergic neurons (Freund and Buzsaki, 1996; Cauli et al., 1997; Kawaguchi and Kubota, 1997; Gupta et al., 2000; McBain and Fisahn, 2001), the presence of specific calciumbinding proteins being just one of them. Parvalbumin-positive neurons constitute an abundant subpopulation and are found in a number of brain regions (Celio, 1990). Electrophysiologically, they have been characterized as fast-firing cells (Kawaguchi et al., 1987), and, in the hippocampus, most of them belong to the group of perisomatic inhibitory neurons (Kosaka et al., 1987; Freund and Buzsaki, 1996; Maccaferri et al., 2000). Recent studies have shown that these cells form extensive reciprocal synaptic connections in different forebrain regions (Sik et al., 1995; Cobb et al., 1997; Tamas et al., 2000). In addition, electrophysiological recordings from pairs of fast-spiking interneurons in the neocortex, hippocampus, striatum, and reticular thalamus have provided evidence for electrical coupling (Galarreta et al., 1999; Gibson et al., 1999; Koos and Tepper, 1999; Venance et al., 2000; Landisman et al., 2002). There is electron microscopical evidence that parvalbumin-positive GABAergic interneurons are coupled by gap junctions in the hippocampus (Katsumaru et al., 1988; Fukuda and Kosaka, 2000). However, it is not clear whether gap 
junction-mediated electrical coupling is a signature of all parvalbumin-positive neurons. Also, the developmental profile of gap junction coupling in identified neurons has remained elusive.

Extensive functional studies of the parvalbumin-positive cell population at the cellular and system level in different brain regions are hampered by the difficulty of identifying these neurons in the acute slice preparation. To facilitate the identification of parvalbumin-positive cells, we took advantage of bacterial artificial chromosome (BAC) technology, which mostly results in transgene expression patterns closely resembling the wild-type genes (Yang et al., 1997; Heintz, 2001). Thus, we introduced the in vivo marker enhanced green fluorescent protein (EGFP) (Chalfie et al., 1994) into the parvalbumin gene carried on a BAC.

Using fluorescence microscopy and immunocytochemistry methods, we show in two mouse lines that EGFP expression is specifically found in parvalbumin-positive neurons. We also illustrate that the expression level of EGFP is high enough to visualize neuronal processes over long distances. Finally, we investigate in these mice the presence of electrical coupling between pairs of parvalbumin-positive neurons in slices obtained from young [postnatal day 14 (P14)] and adult (P28 and P42) brain.

\section{MATERIALS AND METHODS}

Screening of a mouse BAC library and selection of a suitable BAC. A 392 bp probe encompassing 168 bp of intron 4 and exon 5 of the mouse parvalbumin gene was generated by PCR using the following primers: Parv5'stop (CTCAGAGCCTCCATTCCCTC) and Parv3' polyA (AGGTGGTGTCCGATTGGTAC). This probe was used to screen the mouse 129SV strain BAC library (Research Genetics, Inc., Huntsville, AL) spotted onto high-density filters. Southern blot analysis of SalIdigested BAC DNA separated by field inversion pulse gel electrophoresis (FIGE Mapper; Bio-Rad, Hercules, CA) was performed with a 285 bp probe located in the parvalbumin gene promoter region and generated by PCR with the primers mPvPro-1 (AGGTGTGCCCTGCTTGGACCTTA) and mPvPro-2 (CGGAGCCTATACAGAAAAGCT) to determine the size of the $5^{\prime}$-flanking DNA. The amount of 3 '-flanking DNA was determined by Southern blot analysis of HindIII-digested BAC DNA with the probe used to screen the library. The size of the genomic inserts of the BAC clones was determined by NotI digestion and pulse-field gel electrophoresis (PFGE) analysis (CHEF-DRIII; Bio-Rad). Of five BAC clones containing the parvalbumin gene, clone 450D23 was chosen for subsequent EGFP insertion via bacterial homologous recombination. It contained the largest genomic insert $(\sim 180 \mathrm{~kb})$ with $\geq 50 \mathrm{~kb}$ upstream and $15 \mathrm{~kb}$ downstream of the parvalbumin gene.

Introduction of the EGFP into the parvalbumin gene on the BAC. The targeting cassette consisted of the EGFP coding sequence followed by a bovine growth hormone polyadenylation signal flanked by two homologous stretches of genomic DNA located upstream and downstream of the translational start. To obtain DNA sequence information for the generation of recombinogenic arms, the region around the translational start of the parvalbumin gene was sequenced with the following primers: mPvEx25'Seq (GCGGGCAGAGCAAGTGCGAA), mPvEx2-5'Seqb (GGAGGAGGTTGTTGGACTATC), and mPvEx2-3'Seq (GCTGGTGAGCAATGCACCCC). Recombinogenic arms were generated by PCR using the following primers: mPv5'RA-1 (GTCGACCAGGGCTCAGCTAAGGAA), mPv5'RA-2 (CTGCAACTGTTTGAGCGGGCAGAG), mPv3'RA-1 (GCCTTTGCTGGTGAGCAATGCAC), and mPv3'RA-2 (AAGAGATCACACAGCCGAGTGGGT). The amplified 5' recombinogenic arm consisted of $1194 \mathrm{bp}$; the $3^{\prime}$ recombinogenic arm was $612 \mathrm{bp}$. The Pv5' recombinogenic arm was cloned into pIRES-EGFP (BD Bioscience Clontech, Palo Alto, CA), partially digested with NcoI, and filled in with Klenow enzyme to give rise to pIRES-EGFP-5'RA. The $3^{\prime}$ recombinogenic arm was inserted into the EcoRV site of pBluescript II SK (Stratagene, La Jolla, CA) to generate pBS-3'RA. pIRES-EGFP5'RA was digested with $X$ hoI, filled in with Klenow enzyme, and digested again with Bam $\mathrm{HI}$ to release a fragment containing the $5^{\prime}$ recombinogenic arm, the EGFP coding region, and a bovine growth hormone polyadenylation signal. This fragment was inserted into pBS3'RA digested with Bam HI and SmaI to create pBS-Pv5'3'RA-EGFP. The final recombination cassette was released via SalI digestion and cloned into SalI-digested pSV1recA to generate pSV1recA-PvCassette. The method used for the integration of the PvCassette into the translational start of the parvalbumin gene of BAC 450D23 has been described previously (Yang et al., 1997).

Preparation of linearized BAC DNA for pronuclear injection. BAC DNA was prepared by cesium chloride gradient centrifugation. After centrifugation, DNA was taken off the gradient by cutting the top of the tube and taking off the DNA with a 2-ml-wide bore plastic pipette to avoid shearing of the DNA. To release the BAC insert, $50 \mu \mathrm{g}$ of BAC DNA were digested overnight with $\operatorname{Not} \mathrm{I}$ at $37^{\circ} \mathrm{C}$. A CL4B-Sepharose (Amersham Biosciences, Amersham Place, UK) column was equilibrated with $30 \mathrm{ml}$ of injection buffer (in mM: 10 Tris-HCl, pH 7.5, 0.1 EDTA, and 100 $\mathrm{NaCl}$ ) and used to separate the released insert from the vector band. Aliquots of the collected $0.5 \mathrm{ml}$ fractions were run on a PFGE gel to select the fractions used for pronuclear injection.

Generation of transgenic mice. Isolated BAC insert was injected into the pronuclei of B6D2F2 mouse zygotes at a concentration of $0.7 \mu \mathrm{g} / \mathrm{ml}$. Founder animals were analyzed by PCR for the presence and integrity of the integrated BAC using the following primers: EGFP-1 (CCACTAGTGTGAGCAAGGGCGAGGAGCT), EGFP-2 (GGACTAGTGCCGAGAGTGATCCCGGCGGCGGT), BACL-1 (TAACTATGCGGCATCAGAGC), BACL-2 (GCCTGCAGGTCGACTCTAGAG), BACR-1 (GTGTCACCTAAATAGCTTGGCG), and BACR-2 (GGGGTTCGCGTTGGCCGATTC). In the animal with multiple integrated copies, both vector sequences were detected, indicating an intact integration of the BAC. In the animal with a single integrated copy, one vector arm was missing, indicating that the genomic insert of the modified BAC450D23 was not completely integrated into the genome. Copy numbers of the integrated transgene were determined via Southern blot after HindIII digestion of genomic DNA and hybridization with a 5' recombinogenic arm probe. Transgenic mice were bred with C57BL/6 mice. Transmission of the transgene was monitored in the offspring either by PCR using the primers BACL-1/BACL-2, BACR-1/BACR-2, and EGFP-1/EGFP-2 or by detecting EGFP fluorescence through the skin via ultraviolet illumination of the hindlimbs at a wavelength of $366 \mathrm{~nm}$. In both lines, inheritance of the transgene followed Mendelian ratios. In the line with multiple integrated copies, the transgene was detected in $48.2 \%(n=205$ animals) of the offspring, whereas in the line with the single integrated copy, $46.4 \%$ ( $n=114$ animals) of the offspring carried the transgene. Transgenic animals of the $\mathrm{F}_{2}$ generation were used for the evaluation of the EGFP expression pattern. Electrophysiological recordings were obtained from transgenic animals of the $\mathrm{F}_{4}$ and $\mathrm{F}_{5}$ generation. No changes in transgene expression pattern were observed between the different generations.

Immunocytochemical analysis of transgenic mice. Five transgenic animals from each line were used to analyze EGFP expression and coexpression with parvalbumin. Animals were perfused with $4 \%$ paraformaldehyde/PBS, pH 7.4, and 50- $\mu$ m-thick coronal sections were obtained from brain using a Leica (Nussloch, Germany) VT1000S vibratome. The sections were washed in PBS four times for $10 \mathrm{~min}$ at room temperature, permeabilized by incubation in PBS plus $0.2 \%$ Triton X-100 for $30 \mathrm{~min}$ at room temperature, and then incubated with a mouse monoclonal parvalbumin antibody (Sigma-Aldrich, Inc., St. Louis, MO) at a dilution of 1:2000 in PBS for $48 \mathrm{hr}$ at $4^{\circ} \mathrm{C}$. Incubated slices were washed three times with PBS for $10 \mathrm{~min}$ at room temperature, incubated for $2.5 \mathrm{hr}$ at room temperature with a 1:400 dilution of a Texas Red-conjugated anti-mouse IgG (Jackson ImmunoResearch, West Grove, PA) in PBS, and subsequently washed twice in PBS for $10 \mathrm{~min}$ at room temperature. Slices were protected from light during the procedure. Slices were then mounted on slides, embedded in Mowiol, coverslipped, and analyzed using an upright fluorescent microscope (Zeiss Axioplan 2; Zeiss, Göttingen, Germany) equipped with a Zeiss filter set 10 for detection of EGFP (excitation filter BP 450-490; dichroic mirror FT 510; emission filter BP 515-565) and filter set 15 for detection of Texas Red (excitation filter BP 546/12; dichroic mirror FT 580; emission filter LP 590). The confocal image of dentate gyrus basket cells was captured with a Leica (Heidelberg, Germany) TCS-SP2 using an argon laser at $488 \mathrm{~nm}$.

Electrophysiology. The preparation of brain slices from young (P14) and adult (P28 and P42) mice was done as described for rats by Markram et al. (1997). P42 was the oldest age chosen for recordings, because it is widely accepted that neuronal circuits are mature at this age. Recordings were performed at room temperature, and slices were continuously superfused with an extracellular solution containing (in $\mathrm{mm}$ ): $125 \mathrm{NaCl}$, 
A

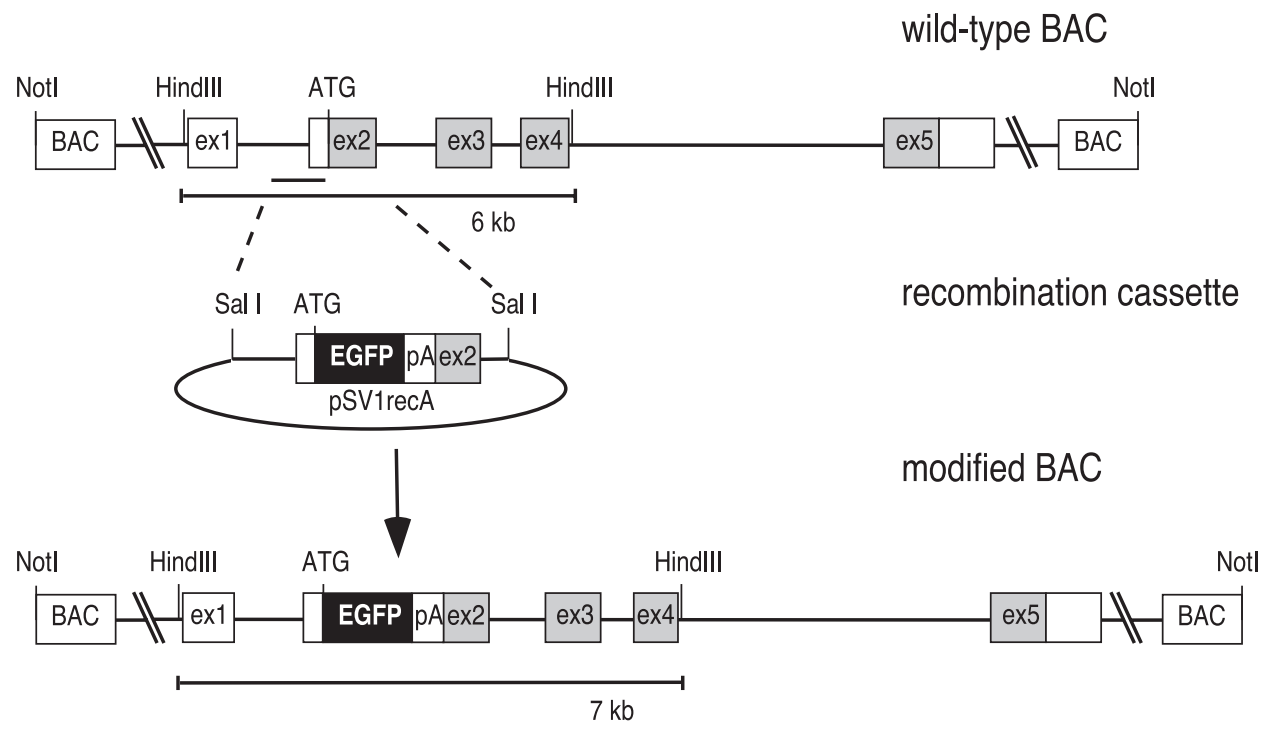

B

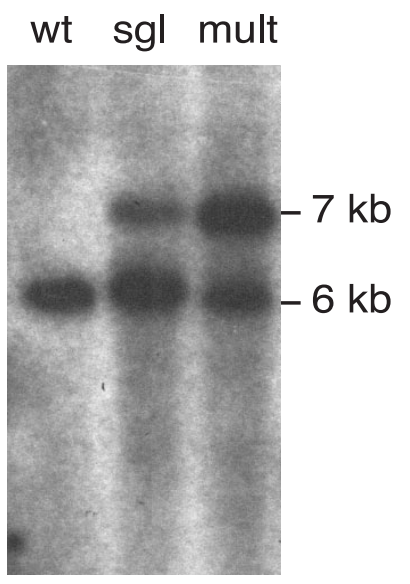

Figure 1. Generation of BAC transgenic animals with EGFP expression in parvalbumin-positive neurons. $A$, Schematic representation of the parvalbumin gene structure, the recombination cassette, and the modified parvalbumin gene located on a BAC. Positions of HindIII and NotI restriction sites are indicated. The PCR fragment used as probe for the Southern blot is indicated as a black bar. B, Southern blot analysis of tail DNA isolated from wild-type and transgenic mice and digested with HindIII to compare signal intensities of the wild-type (6 kb) and transgene (7 kb) band. wt, Wild-type; $s g l$, line with a single integrated copy of the transgene; mult, line with multiple integrated copies of the transgene.

$2.5 \mathrm{KCl}, 25$ glucose, $1.25 \mathrm{NaH}_{2} \mathrm{PO}_{4}, 2 \mathrm{CaCl}_{2}$, and $1 \mathrm{MgCl}_{2}$, bubbled with $95 \% \mathrm{O}_{2} / 5 \% \mathrm{CO}_{2}$. The pipette (intracellular) solution contained (in $\mathrm{mM}$ ): 105 potassium gluconate, $30 \mathrm{KCl}, 10 \mathrm{HEPES}, 10$ phosphocreatinine, 4 ATP-Mg, and 0.3 GTP (adjusted to a pH of 7.3 with $\mathrm{KOH}$ ).

For electrophysiological recordings, slices were placed in the recording chamber under an upright microscope (Axioskop; Zeiss). Individual neurons were identified at $80 \times$ magnification using fluorescence microscopy and subsequent infrared-differential interference contrast (IR-DIC) microscopy. Basket cells and multipolar cells were readily identifiable by EGFP expression, morphology, and action potential firing pattern. No difference in average input resistance, spike width, and firing frequency was observed between EGFP-positive basket cells and multipolar cells and unlabeled basket cells and multipolar cells from wild-type mice (data not shown). Pyramidal cells were identified by morphology and action potential firing pattern.

After we established the whole-cell mode, using patch pipettes with a resistance of 4-8 $\mathrm{M} \Omega$, hyperpolarizing current pulses were applied to one of the potentially coupled neurons. Voltage responses recorded in current-clamp mode from the other cell indicated electrical coupling between these neurons. Recordings were done as described previously (Venance et al., 2000), filtered at $3 \mathrm{kHz}$ and digitized at $10 \mathrm{kHz}$, using an ITC-18 interface (Instrutech, Mineola, NY) and the program PULSE (version 8.21; Heka Elektronik, Lambrecht/Pfalz, Germany). Electrically coupled cells were $<100 \mu \mathrm{m}$ apart both in the tangential and in the vertical dimension. The coupling coefficient was calculated as the ratio of the voltage response in cell 2 divided by the voltage response in cell 1 under steady-state conditions. It was obtained by averaging 15-30 consecutive sweeps and did not depend on which cell from each pair was stimulated. The success rate of finding electrical coupling was calculated as the percentage of electrically coupled pairs out of the total number of pairs tested. Calculation of the statistical significance of differences was performed using unpaired, two-tailed Student's $t$ test.

Biocytin filling. For morphological characterization of the recorded EGFP-positive dentate gyrus basket cells and cortical layer II/III fastspiking multipolar cells, neurons were filled with biocytin $(1-4 \mathrm{mg} / \mathrm{ml})$ dissolved in an internal pipette solution. Subsequently, the slices were fixed overnight in $4 \%$ paraformaldehyde at $4^{\circ} \mathrm{C}$. The biocytin-filled cells were visualized using a Vectastain $\mathrm{ABC}$ Elite kit (Vector Laboratories, Burlingame, CA). Slices were then mounted on slides, embedded in Mowiol, coverslipped, and analyzed under a light microscope (Axioplan 2; Zeiss).

\section{RESULTS}

\section{Generation and expression analysis of EGFP in the transgenic parvalbumin-EGFP mice}

To express the in vivo marker EGFP under the control of the parvalbumin gene promoter, we used BAC transgene technology. The parvalbumin gene consists of five exons spanning a region of $\sim 15 \mathrm{~kb}$ of genomic DNA (Schleef et al., 1992). The EGFP coding region was inserted into the parvalbumin start codon located on exon 2 (Fig. 1A). Two founder animals generated from pronuclear injection of the modified BAC clone, one with a single and one with multiple integrated copies of the transgene (Fig. $1 B)$, were bred and further analyzed. The distribution of parvalbumin-expressing cells in the brain is well established (Kosaka et al., 1987; Celio, 1990). To assess the distribution pattern of EGFP expression in the line with multiple integrated copies, various brain regions known to contain parvalbumin-positive neurons were analyzed by EGFP fluorescence.

In the neoortex, parvalbumin-positive neurons are in layers II to VI. EGFP-fluorescent cells could be seen accordingly throughout all cortical layers except layer I (Fig. $2 A$ ). In the hippocampus, parvalbumin-positive neurons are located in the stratum oriens, stratum pyramidale, and occasionally in the stratum radiatum of the CA3 and CA1 subfields. Accordingly, the majority of EGFPfluorescent cells were found in the stratum pyramidale and oriens, with single dispersed cells in the stratum radiatum and at the border of the stratum radiatum and lacunosum-moleculare. In the dentate gyrus, parvalbumin-positive cells are known to be located most frequently at the border between the stratum granulosum and the hilar region, where the EGFP-fluorescent cells were found (Fig. $2 B$ ). The reticular thalamic nucleus, where all neurons have been described to contain parvalbumin, was visible as a crescent-shaped band of brightly fluorescent cells (Fig. 2C). In the globus pallidus, a population of spatially separated EGFPfluorescent cells was found (Fig. 2D), which corresponds well with 

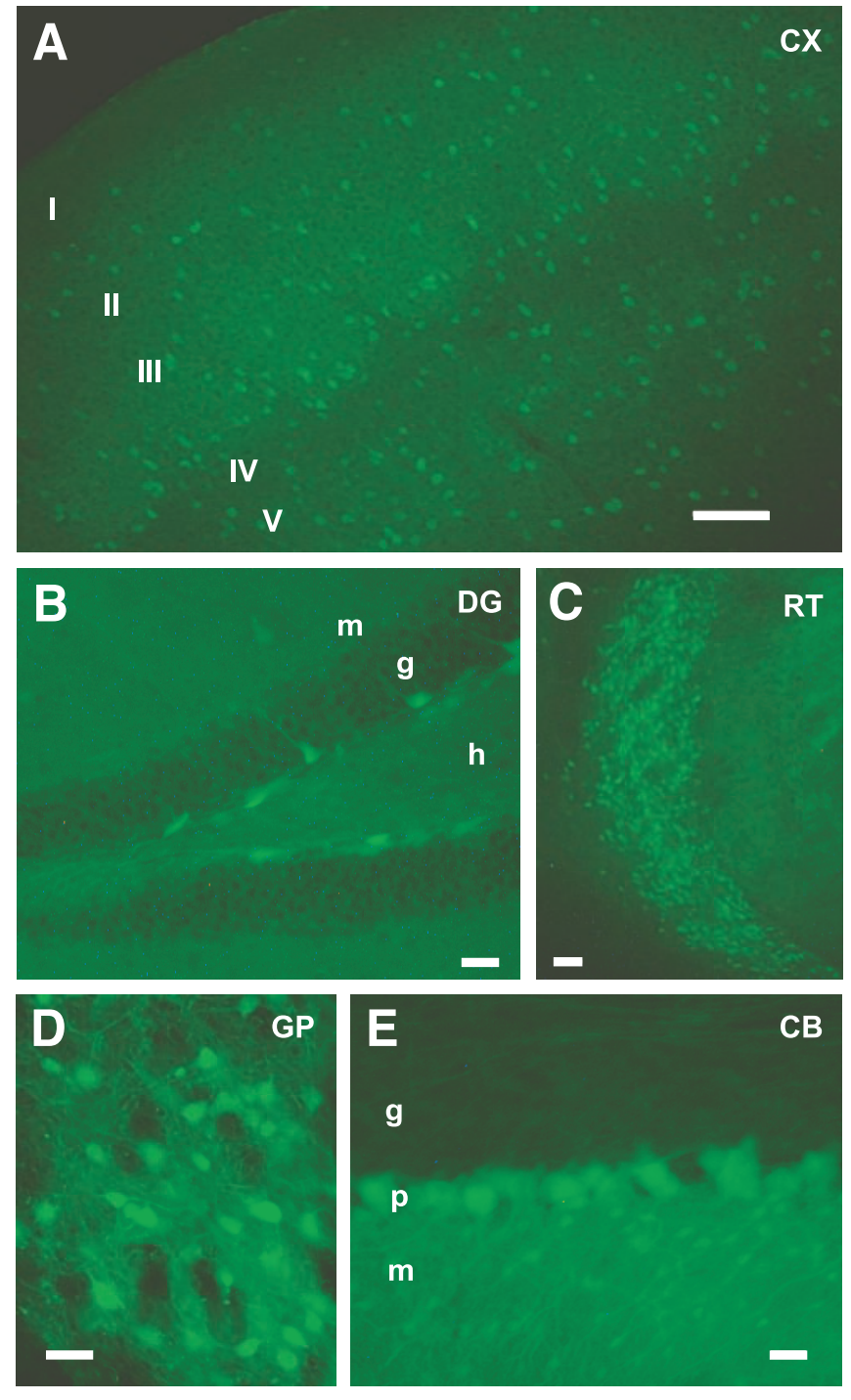

Figure 2. EGFP expression in different brain regions of the line with multiple integrated copies. $A$, In the neocortex, fluorescent cells are visible throughout layers II to VI. $C X$, Cortex; $I, I I, I I I, I V, V$, cortical layers. $B$, In the dentate gyrus $(D G)$, fluorescent cells are visible at the border of the granule cell layer and hilus $(h) . m$, Stratum moleculare; $g$, stratum granulosum. $C$, The reticular thalamic nucleus $(R T)$ is visible as a bright band of fluorescent cells. $D$, Dispersed cells express EGFP in the internal globus pallidus $(G P)$. $E$, In the cerebellum $(C B)$, EGFP fluorescence is detected in Purkinje $(p)$, stellate, and basket cells. $g$, Granule cell layer; $m$, molecular layer. Scale bars: $A, C, 100 \mu \mathrm{m} ; B, D, 50 \mu \mathrm{m} ; E, 20 \mu \mathrm{m}$.

the known distribution of parvalbumin-positive neurons in this region. In the cerebellum, parvalbumin expression is known to be present in Purkinje, stellate, and basket cells, and accordingly, EGFP expression could be found in all three cell types (Fig. 2E).

Likewise, several other areas known to contain parvalbuminpositive neurons were also analyzed and showed correct EGFP expression (the striatum, nucleus accumbens, basolateral amygdala, zona incerta, substantia nigra, and anterior pretectal nucleus) (Table 1). Interestingly, the olfactory bulb, where parvalbumin-positive neurons have been described in the external plexiform layer (Celio, 1990), was the only brain region lacking EGFP expression. Brain regions in which parvalbumin is not expressed (e.g., specific thalamic nuclei) were devoid of EGFP labeling. These results demonstrate that the expression of EGFP

\begin{tabular}{|c|c|}
\hline Brain region & $\%$ Colocalization \\
\hline Cortex & $94.0(n=1418)$ \\
\hline Somatosensory & $94.6(n=922)$ \\
\hline Cingulate & $89.9(n=238)$ \\
\hline Entorhinal & $86.0(n=50)$ \\
\hline Retrosplenial & $98.5(n=208)$ \\
\hline Hippocampus & $47.4(n=268)$ \\
\hline CA1 & $52.1(n=142)$ \\
\hline CA3 & $46.3(n=63)$ \\
\hline DG & $38.1(n=63)$ \\
\hline Hippocampus* & $100(n=77)$ \\
\hline CA1* & $100(n=25)$ \\
\hline CA3* & $100(n=33)$ \\
\hline Dentate gyrus* & $100(n=19)$ \\
\hline Basolateral amygdala & $62.7(n=70)$ \\
\hline Basolateral amygdala* & $100(n=17)$ \\
\hline Striatum & $96.4(n=139)$ \\
\hline Globus pallidus & $95.8(n=72)$ \\
\hline Medial septum & $79.1(n=24)$ \\
\hline Reticular thalamic nucleus & $98.0(n=50)$ \\
\hline Zona incerta & $94.7(n=51)$ \\
\hline Substantia nigra & $98.2(n=57)$ \\
\hline Anterior pretectal nucleus & $100(n=45)$ \\
\hline Cerebellum & $96.1(n=129)$ \\
\hline Purkinje cells & $100(n=65)$ \\
\hline Stellate and basket cells & $92.2(n=64)$ \\
\hline
\end{tabular}

Intrinsic EGFP fluorescence was compared with red antiparvalbumin staining in a cell-by-cell manner in the various brain regions (\% colocalization determined as the number of EGFP-positive cells expressing parvalbumin). Data obtained from mice with a single integrated transgene copy are marked by an asterisk.

is indeed restricted to brain areas in which native parvalbumin expression occurs.

Given the very good correspondence between regional EGFP expression patterns and patterns of parvalbumin expression described previously, we also analyzed the fidelity of transgene expression at the cellular level. Coexpression of parvalbumin and EGFP was evaluated by combining the intrinsic green fluorescence of EGFP with red fluorescent immunostaining for parvalbumin. An almost complete overlap of EGFP and parvalbumin expression was found in most brain regions (Table 1). We could not detect any parvalbumin-positive neurons that were EGFP negative. Conversely, there were only few EGFP-positive neurons that were parvalbumin negative. Thus, in the neocortex, EGFP was coexpressed with parvalbumin in $94 \%$ of the EGFPexpressing cells $(n=1418)$ (Fig. $3 A, B)$. In the reticular thalamic nucleus, the coexpression analysis of EGFP and parvalbumin showed an almost complete overlap; 98\% of the EGFP-positive cells were parvalbumin positive $(n=50)$ (Fig. $3 C, D)$. In the internal globus pallidus, EGFP expression was also primarily restricted to parvalbumin-positive cells, showing a $96 \%$ overlap $(n=72)$ (Fig. $3 E, F)$. In the cerebellum, 92\% of the EGFPexpressing cells were parvalbumin positive $(n=129)$ (Fig. 3G,H). In the hippocampus (Fig. $4 A, B$ ) and amygdala, EGFP and parvalbumin colocalized to a lesser degree (Table 1). However, in the mouse line with the single integrated copy of the transgene, a complete overlap of EGFP and parvalbumin was found in these brain regions as well (Fig. $4 C, D$; Table 1 ).

In the line with multiple integrated copies of the transgene, 

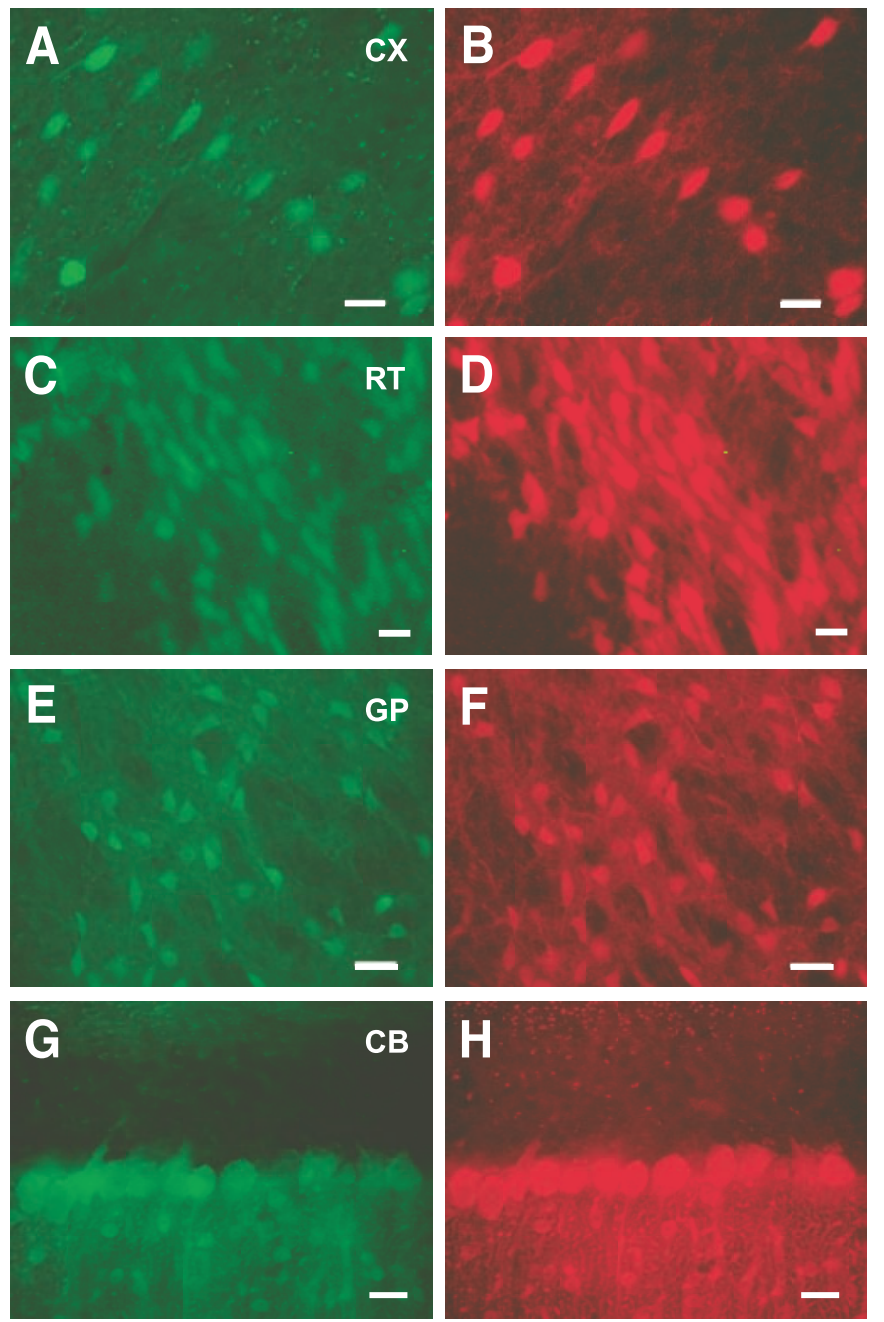

Figure 3. EGFP and parvalbumin expression patterns strongly overlap in several brain regions. Coexpression is determined in $50-\mu \mathrm{m}$-thick sections, which were immunocytochemically processed for parvalbumin, by comparing EGFP fluorescence $(A, C, E, G)$ with parvalbumin antibody staining $(B, D, F, H)$. Representative examples are shown from the cortex $(C X ; A, B)$, reticular thalamic nucleus $(R T ; C, D)$, globus pallidus $(G P ; E$, $F)$, and cerebellum $(C B ; G, H)$. Scale bars: $A-H, 20 \mu \mathrm{m}$.

EGFP expression was high enough to visualize neuronal processes. Dentate gyrus basket cells have large cell bodies located at the border of the granular layer and the hilar region, with a prominent apical dendrite projecting into the granule cell layer. Apart from the cell body, the apical dendrites projecting into the granule cell layer as well as the basal dendrites of EGFP-labeled basket cells were readily visible under a confocal microscope (Fig. 5A).

Next, we investigated whether the expression of the transgene resembles not only the regional but also the temporal expression pattern of parvalbumin. Parvalbumin expression is first detected in several neocortical regions at P10 in single neurons in layer V from which it spreads to the other cortical regions and layers until P14 (Del Rio, 1994). In accordance with this study, we could detect the first visible EGFP-expressing cells in layer $\mathrm{V}$ of the neocortex at P11. At P14, EGFP expression is detectable throughout all cortical layers except layer I (data not shown). These results indicate that the $\mathrm{BAC}$ harboring the parvalbumin gene contained all necessary control elements that ensure correct temporal and regional expression of the transgene.
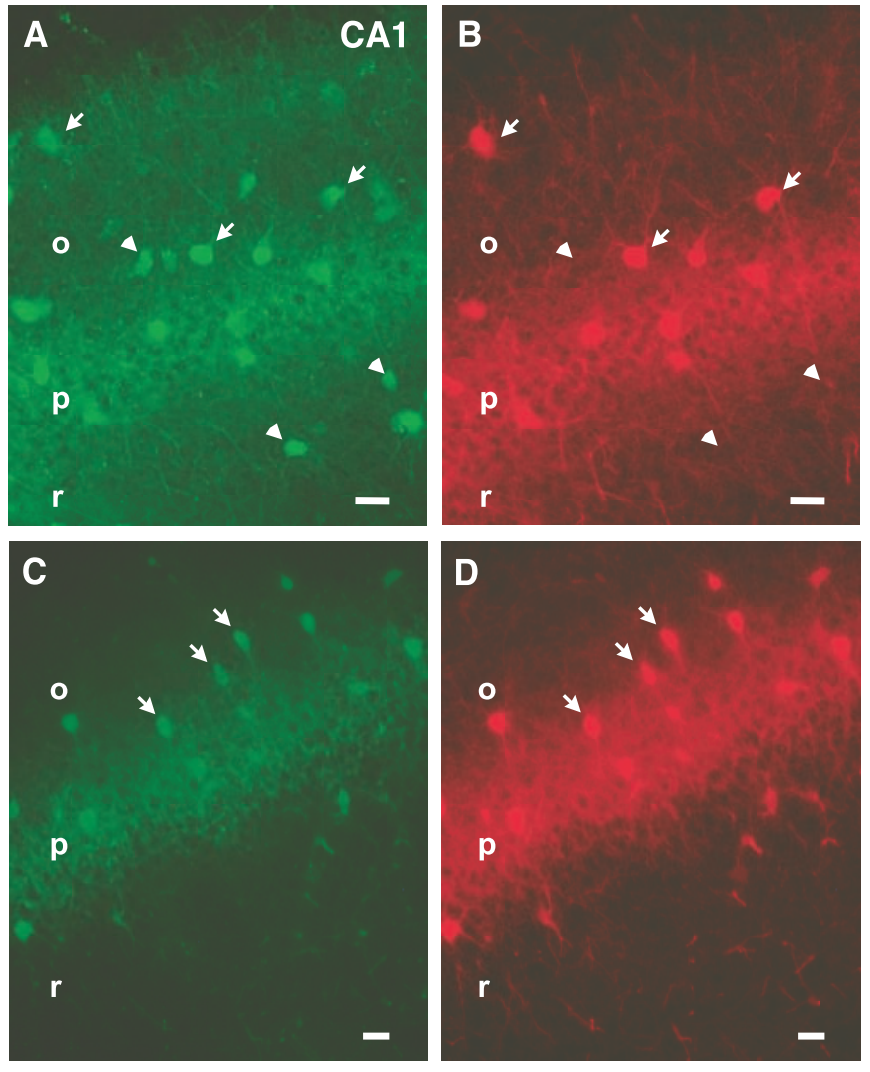

Figure 4. Comparison of the coexpression of EGFP and parvalbumin in the CA1 region of the hippocampus in the two transgenic mouse lines. Coexpression is determined as in Figure 3. Comparison of EGFP fluorescence $(A, C)$ with parvalbumin immunocytochemistry $(B, D)$ showed an incomplete overlap in the mouse line with multiple integrated copies of the transgene $(A, B)$, whereas in the mouse line with a single integrated copy of the transgene, a complete overlap was found $(C, D)$. Arrows, Representative examples of EGFP and parvalbumin coexpression; arrowheads, nonoverlapping expression of EGFP and parvalbumin. Scale bars: $A-D, 20 \mu \mathrm{m}$. $C A 1$, CA1 subfield of the hippocampus; $o$, stratum oriens; $p$, stratum pyramidale; $r$, stratum radiatum.

\section{Electrical coupling between identified labeled neurons}

In the dentate gyrus, basket cells were easily identified by EGFP fluorescence (Fig. 6A). Recorded EGFP-positive cells exhibited high-frequency action potential firing patterns (Kawaguchi et al., 1987; Koh et al., 1995). Recorded cells, which were filled with biocytin, showed the typical morphology and location of dentate gyrus basket cells (Figs. 5B, 6B). In slices obtained from P14 mice, the majority of dentate gyrus basket cells was coupled via gap junctions, as has been shown previously in juvenile rats (Venance et al., 2000). Reciprocal electrical coupling was present in 12 of 13 pairs $(92.3 \%)$ of EGFP-positive, fast-spiking interneurons (Fig. 6C,E). The voltage responses in the first basket cell in response to current injection were reflected in the second basket cell and vice versa. Action potentials elicited in one cell were reflected in the other cell (Fig. 6D). Hyperpolarizing responses in pairs of dentate gyrus basket cells were transmitted in a strongly attenuated manner from one cell to the other [coupling coefficient, $0.029 \pm 0.017$ (mean $\pm \mathrm{SD} ; n=12$ pairs)]. On average, the coupling coefficient did not depend on which of the two cells in a pair was stimulated, indicating that electrical coupling was symmetrical (data not shown). Both incidence and strength of electrical coupling decrease with age. At P28, 5 of 10 tested basket cell pairs $(50 \%)$ were found to be coupled (Fig. $6 E$ ). The coupling 

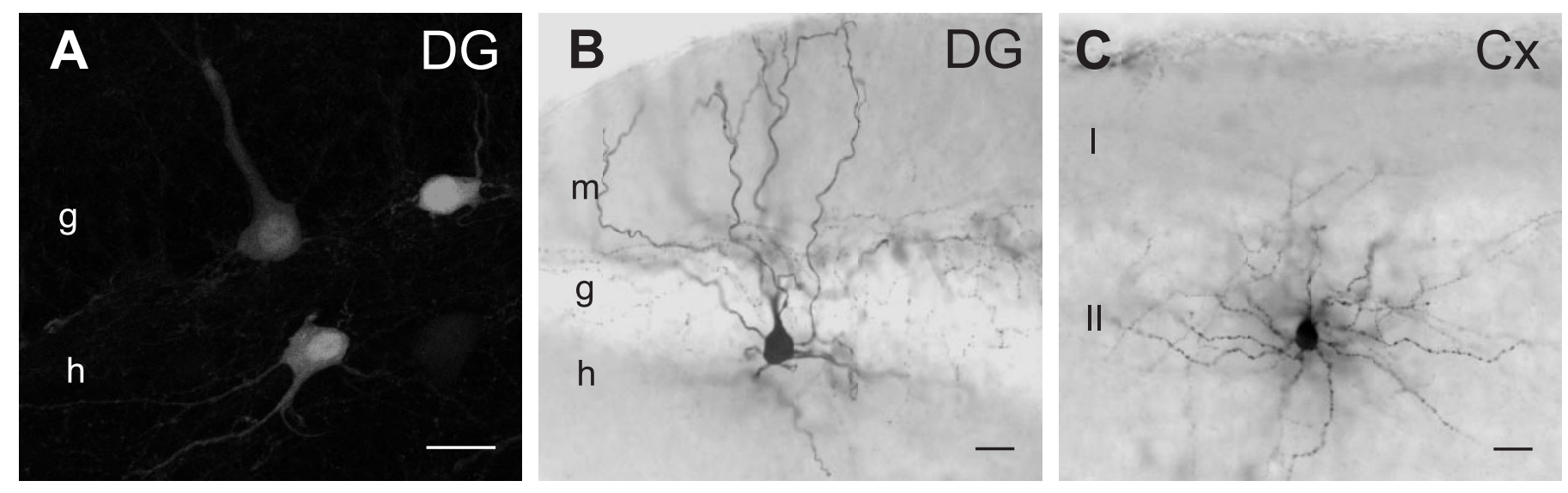

Figure 5. Morphology of EGFP-expressing neurons in the line with multiple integrated copies. $A$, The fluorescently labeled dendrites of EGFP-positive dentate gyrus $(D G)$ basket cells located at the border of the granule cell layer and the hilus $(h)$ are clearly visible under a confocal microscope. $B$, Light microscopic image of a biocytin-filled, EGFP-positive dentate gyrus basket cell reveals the typical morphology. $C$, Light microscopic image of a biocytin-filled, EGFP-positive layer II multipolar cell. Scale bars: $A-C, 20 \mu \mathrm{m}$. $m$, Stratum moleculare; $g$, stratum granulosum; $C x$, cortex; $I, I I$, cortical layers.

coefficient was $0.017 \pm 0.016$ ( $n=5$ pairs). A further reduction of both incidence and strength of coupling was detected in P42 brain slices, in which we found that only 4 of 13 tested basket cell pairs $(30.7 \%)$ were coupled with a coupling coefficient of $0.012 \pm 0.004$ ( $n=4$ pairs). The coupling coefficient was significantly reduced in P42 compared with P14 animals ( $p=0.034)$.

In the neocortex, electrically coupled, fast-spiking multipolar cells have been described in deep cortical layers (Galarreta et al., 1999; Gibson et al., 1999). We extended our analysis to other layers and investigated gap junction coupling between identified parvalbumin-positive, EGFP-positive, fast-spiking multipolar cells in layer II/III. Biocytin filling of recorded fast-spiking multipolar cells revealed the typical morphology of this cell type (Figs. $5 C$, $7 A$ ). Unlike in dentate gyrus basket cells, we found that in layer II/III fast-spiking multipolar cells, the high degree of electrical coupling observed in P14 brain slices is maintained in the adult brain at P28 and P42. Electrical coupling was detected in 9 of 10 pairs (90\%) (Fig. 7B,C) in P14 brain slices. At P28, eight of eight pairs $(100 \%)$ were found to be coupled, and at P42, eight of nine pairs of multipolar cells (89\%) showed electrical coupling (Fig. $7 B, C)$. Also, the strength of electrical coupling remains unchanged between coupled pairs of layer II/III fast-spiking multipolar cells during development. The coupling coefficient was $0.025 \pm 0.018(n=9$ pairs $), 0.02 \pm 0.014$ ( $n=8$ pairs $)$, and $0.034 \pm 0.025$ ( $n=8$ pairs) at P14, P28, and P42, respectively (Fig. $7 C$ ). The coupling coefficient was not significantly different in P42 compared with P14 animals ( $p=0.16$ ).

In the adult mouse hippocampus and neocortex, the major gap junction-forming neuronal connexin, connexin 36 (Cx36), appears to be preferentially expressed in GABAergic interneurons (Belluardo et al., 2000). In situ hybridization studies, however, show a wider distribution at earlier developmental stages (Belluardo et al., 2000). Given the lack of developmental changes regarding electrical coupling between fast-spiking multipolar cells in layer II/III, we subsequently tested whether gap junction coupling between fast-spiking multipolar cells and principal cells in layer II/III of the neocortex could be found. Although not frequent, this type of connection was found in the P14 brain in 5 of 57 tested pairs $(8.7 \%$ ) (Fig. 8A,B). The strength of electrical coupling between these two cell types was weaker than the connection between layer II/III fast-spiking multipolar cells (cou- pling coefficient, $0.014 \pm 0.009 ; n=5$ pairs) (Figs. $7 C, 8 B$ ). This type of connection seems to be absent from the adult brain already at P28, because we could not detect electrical coupling between fast-spiking multipolar cells and pyramidal cells in 50 tested pairs (Fig. 8B).

Since we observed that gap junction coupling is differentially regulated during development, we compared the basic electrophysiological properties of the studied cells in P14 and P42 animals. No age-dependent difference in average input resistance and firing frequency was found for EGFP-positive basket cells and multipolar cells. In both cell types, the half-width of an action potential became significantly shorter at later developmental stages (Table 2). The fact that input resistance does not change in basket cells from P14 to P42 strongly suggests that the observed decrease in coupling coefficient is not attributable to changes of membrane properties in these cells. However, functional properties of gap junctions themselves could change with age and thereby lead to a reduced conductance of electrical synapses and consequently to a decrease in coupling coefficient. In addition to the resistance of electrical synapses, a number of other factors contribute to low-pass filtering, including voltage-gated channels, dendritic length constant, and dendritic arborization. Because the latter parameters can be considered to be the same in cells of the same type, the contribution of the gap junctions can be estimated by calculating the ratio of the time constants of the rising component of the voltage responses measured in cell 1 and cell 2 . These values can be compared between ages to estimate possible changes in the functional properties of the electrical synapse. The logic behind this analysis is the following: the time constant of the rising component of the voltage response in the receiving cell $\left(\tau_{2}\right)$ depends on membrane capacity $(\mathrm{Cm})$, membrane resistance $(\mathrm{Rm})$, and resistance of gap junctions $(\mathrm{Rg})$ and can be described as $\tau_{2}=(\mathrm{Rm}+\mathrm{Rg})(\mathrm{Cm})$, whereas tau of the response measured in the injected cell is $\tau_{1}=(\mathrm{Rm})(\mathrm{Cm})$. The ratio $\tau_{2} / \tau_{1}$ is $1+$ $(\mathrm{Rg} / \mathrm{Rm})$. Obviously, the ratio strongly depends on the resistance of electrical synapses $(\mathrm{Rg})$, especially because we showed that input resistance $(\mathrm{Rm})$ does not change during development. Time constants were calculated by fitting the voltage traces with a monoexponential fit (Fig. 8C). The ratios calculated for P14 and P42 dentate gyrus basket cells were $2.52 \pm 0.32$ (mean $\pm \mathrm{SD} ; n=$ $5)$ and $2.62 \pm 0.11(n=4 ; p=0.69)$, respectively. These values 

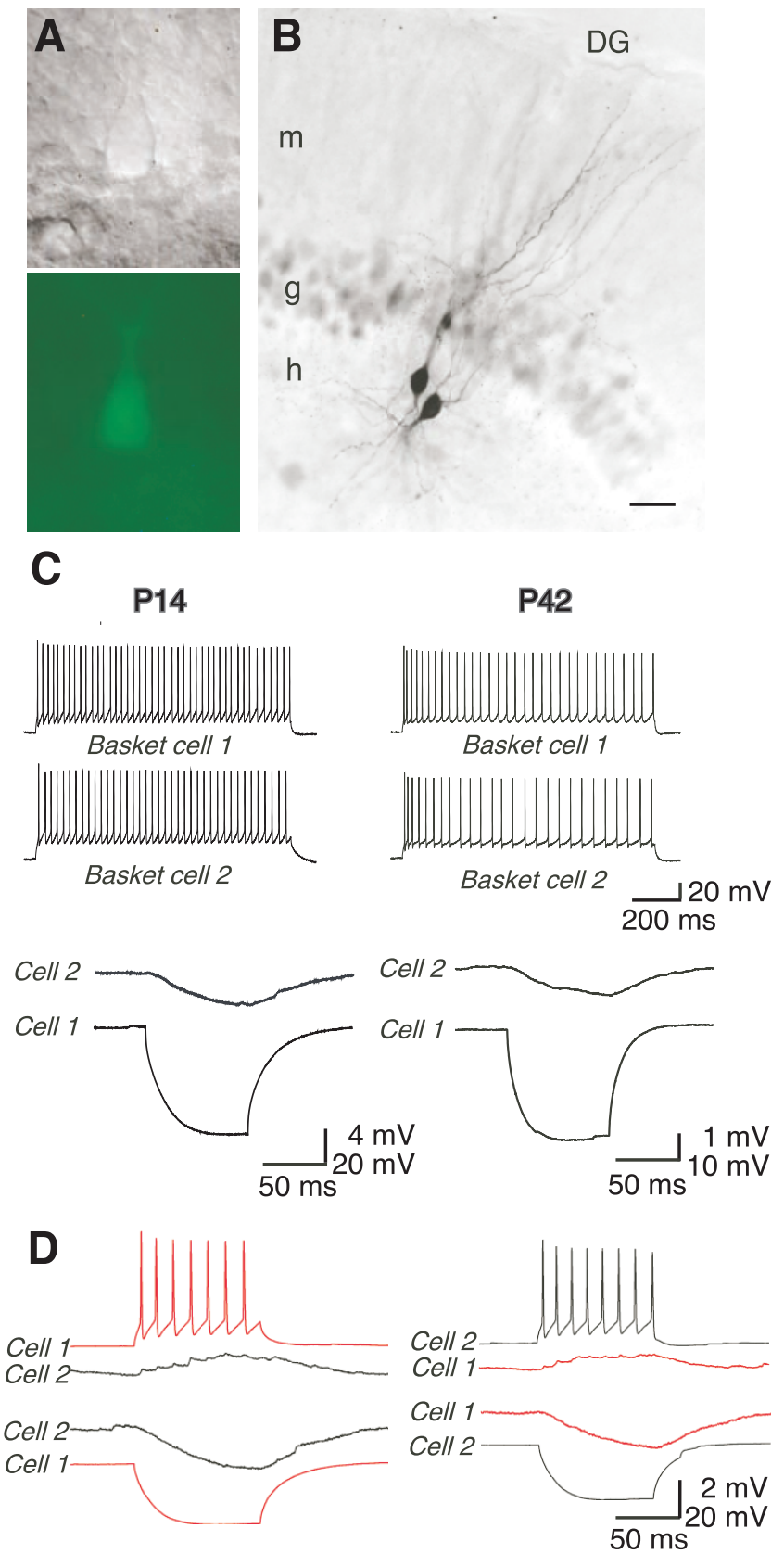

E
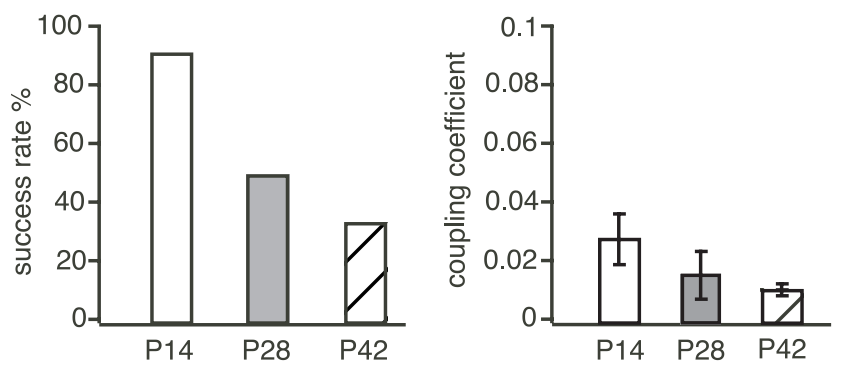

Figure 6. Electrical coupling between pairs of dentate gyrus $(D G)$ basket cells in young (P14) and adult (P28 and P42) mice. A, IR-DIC (top) and fluorescence microscopy image (bottom) of an EGFP-positive dentate gyrus basket cell showing the typical morphology. $B$, Light microscopic image of a biocytin-filled, EGFP-positive pair of dentate gyrus basket cells. $C$, Firing patterns of basket cells from a P14 and P42 brain that were electrically coupled. The voltage response of cell 1 after current injection were similar to ratios obtained for layer II/III multipolar cells $[2.79 \pm 0.37(n=5)$ for P14 and $2.73 \pm 0.38(n=5 ; p=0.8)$ for P42]. Thus, the conductance of gap junctions does not change during development and does not differ between different cell types. The reduction in the coupling coefficient that we observed between dentate gyrus basket cells at later developmental stages therefore most likely reflects a reduced expression level of connexins rather than a functional modification of electrical synapses themselves.

\section{DISCUSSION}

We have demonstrated in this study how subsets of GABAergic interneurons can be targeted and functionally analyzed by generating transgenic mice in which the marker EGFP is expressed under the control of a cell type-defining gene carried on a BAC. We chose to label the parvalbumin-positive neurons because functional studies had indicated that this subpopulation of GABAergic interneurons may play an important role in network synchrony (Tamas et al., 2000). Identification of parvalbuminpositive neurons in the live slice or animal before commencing electrophysiological or anatomical studies would be a significant aid for the systematic study of this cell population at the cellular and system level.

The EGFP expression pattern in the transgenic mice largely corresponds to that of the defining parvalbumin gene because the BAC with its large DNA insert contains the regulatory elements of the gene embedded in their natural DNA environment. Therefore, untoward effects on EGFP expression, such as ectopic and mosaic expression caused by chromosomal sequences surrounding the insertion site of the transgene, are minimized (Heintz, 2001). Attempts to specifically label neuronal populations with GFP or its spectral variants by using short promoter fragments have been reported previously (Feng et al., 2000; Oliva et al., 2000). These attempts were either not successful in labeling the complete set of targeted neurons or resulted in a strong line-toline variation of EGFP expression. The high specificity and reliability of the EGFP expression pattern we found confirms the expectation that the use of BACs allows the creation of an expression pattern closely resembling that of the original gene (Yang et al., 1997; Zuo et al., 1999; Heintz, 2000). Therefore, BAC transgenes are particularly well suited for labeling complete neuronal populations defined by the expression of certain marker genes. However, BAC transgenes do not guarantee a perfect recapitulation of the expression pattern of the cell type-defining gene, as evidenced by the lack of EGFP expression in the olfactory bulb.

Remarkably, in our study, EGFP was expressed at high enough levels to allow visualization of dendritic structures, without EGFP being fused to dendritic marker proteins such as growthassociated protein-43 (Moriyoshi et al., 1996).

Using these mice as a tool, we analyzed electrical coupling of labeled neurons in the dentate gyrus and neocortex. A number of recent studies demonstrated electrical coupling between specific

$\leftarrow$

is also detectable in cell 2 , although with a significantly reduced amplitude. $D$, Electrical coupling is reciprocal between P14 dentate gyrus basket cells. $E$, Two histograms showing the success rate of finding electrical coupling in dentate gyrus basket cells and the coupling coefficients found in these pairs at P14 (white boxes), P28 (gray boxes), and P42 (hatched boxes). Error bars represent SD. Scale bar: $B, 20 \mu \mathrm{m}$. $m$, Stratum moleculare; $g$, stratum granulosum; $h$, hilus. 


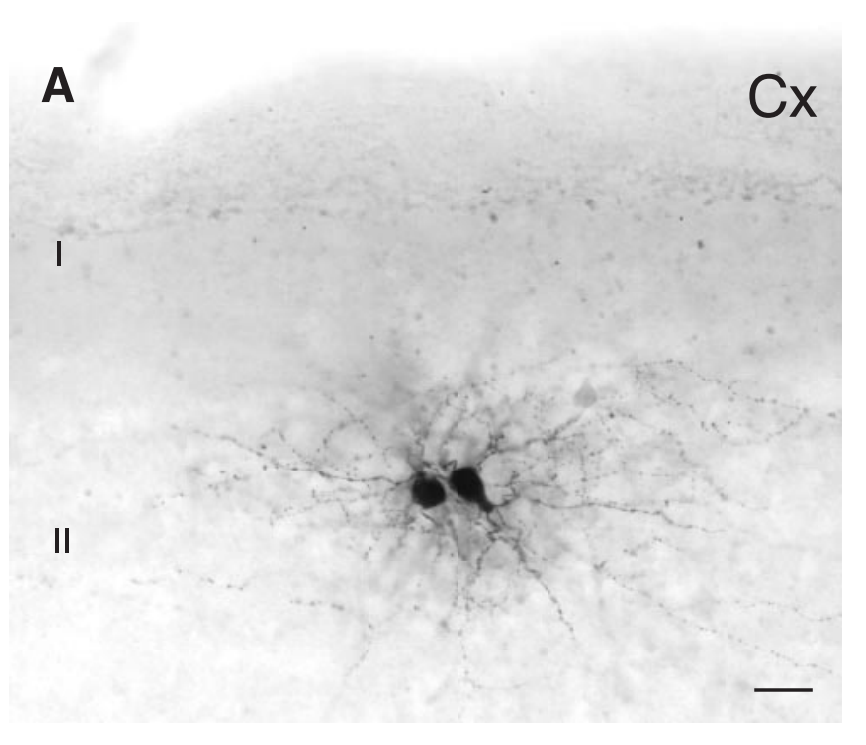

B
P14
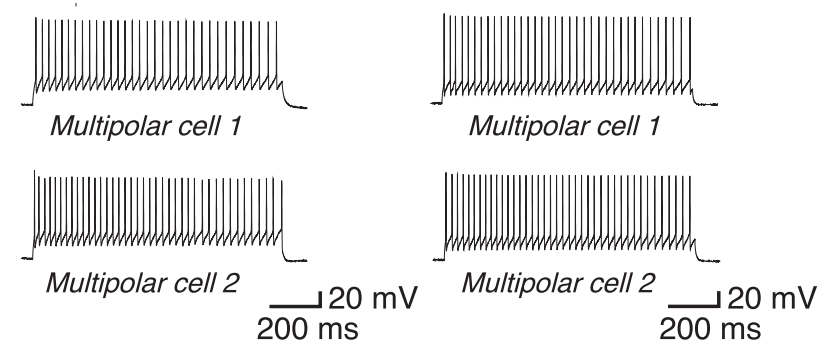

\section{P42}

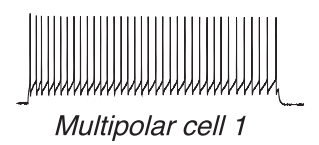

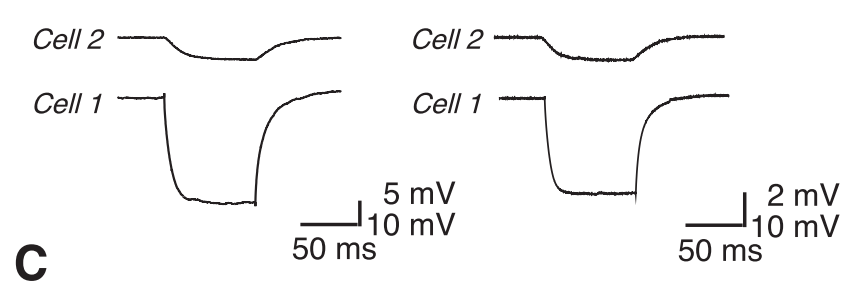
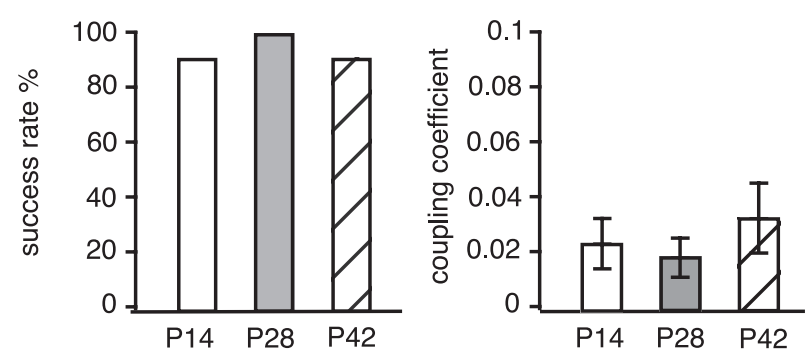

Figure 7. Electrical coupling between layer II/III neocortical neurons. $A$, Light microscopic image of a biocytin-filled, EGFP-positive pair of layer II/III fast-spiking multipolar cells. $B$, Firing patterns of layer II/III fast-spiking multipolar cells from a P14 and P42 brain that were electrically coupled. The voltage response of cell 1 after current injection is also detectable in cell 2, although with a significantly reduced amplitude. $C$, Two histograms showing the success rate of finding electrical coupling in layer II/III fast-spiking multipolar cells and the coupling coefficients found in these pairs at P14 (white boxes), P28 (gray boxes), and P42 (hatched boxes). Error bars represent SD. Scale bar: $A, 20 \mu \mathrm{m} ; C x$, Cortex; $I, I I$, cortical layers.
A
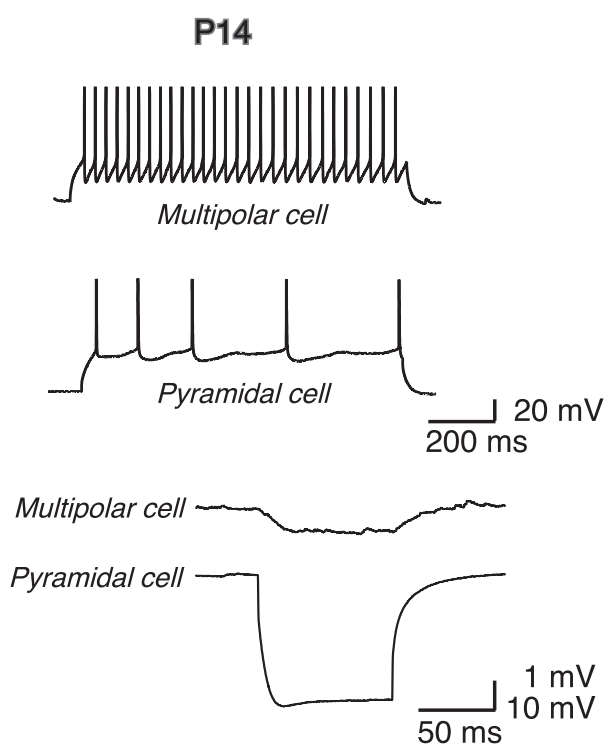

B
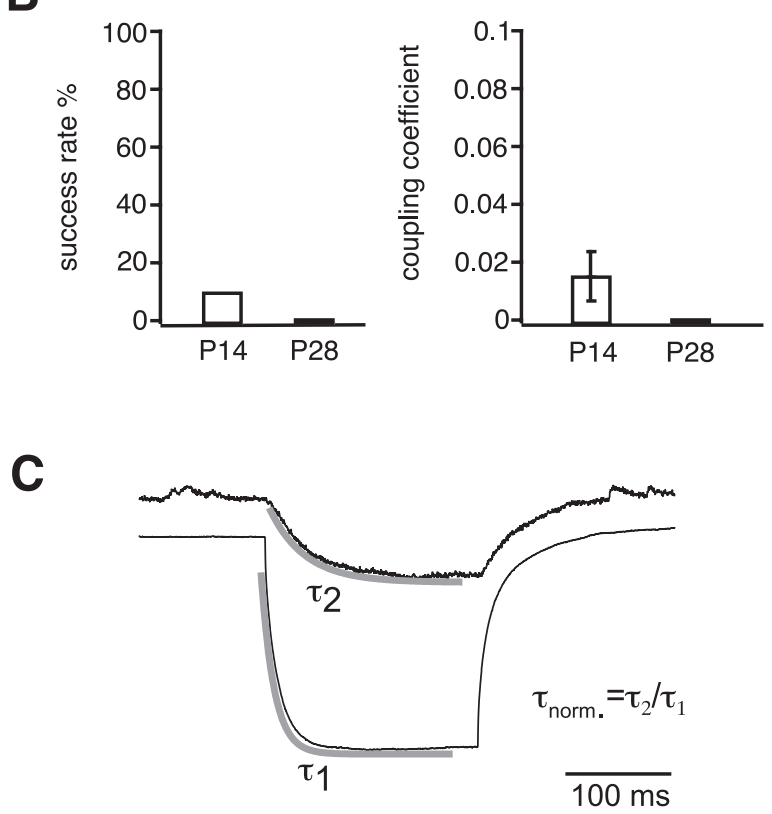

Figure 8. Electrical coupling between neocortical layer II/III fast-spiking multipolar and pyramidal cells. $A$, Firing patterns of a layer II/III fastspiking multipolar cell and principal cell. The voltage response of the pyramidal cell after current injection is also detectable in the multipolar cell. $B$, Two histograms showing the success rate of finding electrical coupling in layer II/III fast-spiking multipolar cells and the coupling coefficients found in these pairs at P14 (white boxes) and P28 (gray boxes). Error bars represent SD. $C$, Estimation of the gap-junctional contribution to low-pass filtering. Voltage traces were fitted with a monoexponential fit ( gray curves), and the normalized time constant $\left(\tau_{\text {norm }}\right)$ was calculated by dividing $\tau_{2}$ by $\tau_{1}$.

GABAergic interneuron subtypes in the postnatal brain (Galarreta et al., 1999; Gibson et al., 1999; Venance et al., 2000; Landisman et al., 2002). For technical reasons, these studies, our own included, were preferentially performed in brain slices from young animals, because the viability of cells in slices obtained from adult animals is significantly reduced. Thus, functional studies of specific cell types that are not readily found are a difficult if not impossible enterprise in the adult. Because 
Table 2. Comparison of basic electrophysiological parameters obtained for dentate gyrus basket cells and layer II/III fast-spiking multipolar cells at two developmental stages (P14 and P42)

\begin{tabular}{lcccc} 
Cell type & Age & Input resistance $(\mathrm{M} \Omega)$ & Firing frequency $(\mathrm{Hz})$ & $\begin{array}{c}\text { Action potential } \\
\text { half-width }(\mathrm{msec})\end{array}$ \\
\hline DG basket & $\mathrm{P} 14$ & $110 \pm 42.7$ & $82 \pm 30.3$ & $1.01 \pm 0.2^{*}$ \\
DG basket & $\mathrm{P} 42$ & $91.5 \pm 42$ & $90 \pm 19.6$ & $0.76 \pm 0.13^{*}$ \\
Mult & P14 & $82 \pm 24.5$ & $40.6 \pm 5.6$ & $0.99 \pm 0.1^{* *}$ \\
Mult & P42 & $76 \pm 18.9$ & $45.6 \pm 6.2$ & $0.68 \pm 0.1^{* *}$ \\
\hline
\end{tabular}

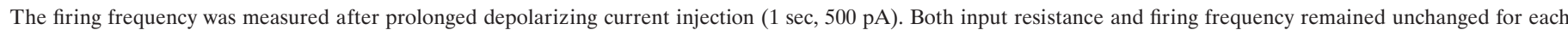

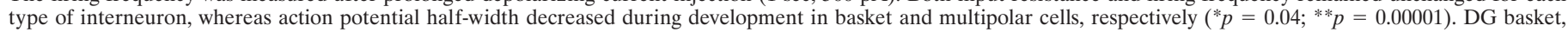
Dentate gyrus basket cells; Mult, layer II/III fast-spiking multipolar cells.

parvalbumin-positive interneurons can easily and quickly be found in acute slices of the transgenic mice that we generated, persistence and strength of electrical coupling in the adult could be analyzed.

Electrical coupling is mediated by gap junctions (for review, see Bennett, 1997); in GABAergic interneurons, gap junction channels are primarily formed of $\mathrm{Cx} 36$, which is primarily a neuronal connexin (Condorelli et al., 1998; Söhl et al., 1998). Its expression can be detected as early as embryonic day 9.5, with a rise in the postnatal brain until P7 and a subsequent decrease to adult levels (Söhl et al., 1998; Gulisano et al., 2000). Nothing is known, however, about the developmental regulation of $\mathrm{Cx} 36$ expression in parvalbumin-positive neurons. It is not clear whether the overall decrease in Cx36 mRNA expression as indicated by in situ hybridization $\mathrm{x}$-ray film autoradiography is also reflected at the cellular level in this specific cell population. From studies on slices from Cx36 knock-out mice, it could be inferred indirectly that electrical coupling persists in adult GABAergic interneurons, because gamma oscillatory activity is altered in slices from knockout mice (Hormuzdi et al., 2001). However, nothing is known about the developmental change regarding the degree and incidence of coupling in parvalbumin-positive interneurons. The transgenic mice with EGFP-labeled GABAergic interneurons enabled us to address these questions. We chose to analyze the strength and incidence of coupling between identified interneurons in slices obtained from young (P14) and adult (P28 and P42) animals. By P42, the maturation of the cortex can be considered completed even in the visual cortex, which is known to mature later than other cortical structures (Gordon et al., 1996; Fagiolini et al., 2000).

Electrical coupling was first investigated in parvalbuminpositive dentate gyrus basket cells. In these cells, electrical coupling persists in the adult (P42), although both the incidence and the strength of coupling are reduced compared with the young (P14) animals. This is in contrast to the results obtained in a neocortical type of parvalbumin-positive cell, the layer II/III fast-spiking multipolar interneurons. In these cells, the incidence and strength of electrical coupling are comparable in the young (P14) and adult (P42) animals. Of note is that at P14, layer II/III multipolar interneurons are not coupled only among themselves but also with pyramidal cells. Electrical coupling between pyramidal and multipolar neurons, however, is absent already at P28. Thus, in the three types of neuronal pairs studied here, electrical coupling showed a cell type-specific change during development: reduced coupling in pairs of basket cells, unaltered coupling in pairs of multipolar cells, and disappearance of coupling in pairs of multipolar-pyramidal cells.

These results support the notion that cell type-specific electrical coupling serves different functions in the young and adult brain. During the first two postnatal weeks, the more widespread and higher expression level of Cx36 mRNA (Söhl et al., 1998; Belluardo et al., 2000; Hormuzdi et al., 2001) is also reflected in functional studies: electrical coupling is found between pairs of various GABAergic interneurons of the same type but also between pairs of cells that are different, such as shown here in the case of multipolar cell-pyramidal cell coupling. In a previous study, we identified the presence of electrical coupling between two other different cell types: the fusiform somatostatin-positive cell (a GABAergic interneuron) and the spiny stellate cell (a glutamatergic neuron) in the somatosensory cortex in the young brain (Venance et al., 2000). In the adult cortex however, electrical coupling occurs preferentially between interneurons of the same type. Similar developmental changes occur also in the hippocampal CA3 region, in which $\mathrm{Cx} 36$ is present in pyramidal cells and GABAergic interneurons in the young but can no longer be detected, at least by in situ hybridization or single-cell PCR, in adult pyramidal cells (Hormuzdi et al., 2001). More frequent and stronger electrical coupling occurring in the young may be involved in the generation of giant GABAergic potentials described in the hippocampus (Ben-Ari et al., 1989; Strata et al., 1997). In addition, gap junctions have been shown to mediate the coactivation of small "neuronal domains" (Yuste et al., 1992, 1995; Peinado et al., 1993; Kandler and Katz, 1998) as well as cortical large-scale wavelike activity (Peinado, 2000, 2001) during early postnatal development. However, in the adult, electrical coupling of GABAergic interneurons, which is mediated to a large extent, if not exclusively, through Cx36 forming gap junctions, plays an important role in the generation of robust oscillatory activity in the gamma-range frequencies (Hormuzdi et al., 2001).

In summary, we demonstrate in this study the generation of transgenic mice with specific EGFP labeling of parvalbuminpositive cells. These mice are a significant aid for the functional characterization of this cell type in different brain regions in the young and adult animal, electrical coupling being just one of the many features that warrant a systematic approach.

\section{REFERENCES}

Beierlein M, Gibson JR, Connors BW (2000) A network of electrically coupled interneurons drives synchronized inhibition in neocortex. Nat Neurosci 3:904-910.

Belluardo N, Mudo G, Trovato-Salinaro A, Le Gurun S, Charollais A, Serre-Beinier V, Amato G, Haeflinger JA, Meda P, Condorelli DF (2000) Expression of connexin36 in the adult and developing rat brain. Brain Res 865:121-138.

Ben-Ari Y, Cherubini E, Corradetti R, Gaiarsa JL (1989) Giant synaptic potentials in immature rat CA3 hippocampal neurones. J Physiol (Lond) 416:303-325.

Bennett MV (1997) Gap junctions as electrical synapses. J Neurocytol 26:349-366.

Cauli B, Audinat E, Lambolez B, Angulo MC, Ropert N, Tsuzuki K, Hestrin S, Rossier J (1997) Molecular and physiological diversity of cortical nonpyramidal cells. J Neurosci 17:3894-3906. 
Celio M (1990) Calbindin D-28k and parvalbumin in the rat nervous system. Neuroscience 35:375-475.

Chalfie M, Tu Y, Euskirchen G, Ward WW, Prasher DC (1994) Green fluorescent protein as a marker for gene expression. Science 263:802-805.

Cobb SR, Buhl EH, Halasy K, Paulsen O, Somogyi P (1995) Synchronization of neuronal activity in hippocampus by individual GABAergic interneurons. Nature 378:75-78.

Cobb SR, Halasy K, Vida I, Nyiri G, Tamas G, Buhl EH, Somogyi P (1997) Synaptic effects of identified interneurones innervating both interneurones and pyramidal cells in the rat hippocampus. Neuroscience 79:629-648.

Condorelli DF, Parenti R, Spinella F, Trovato-Salinaro A, Belluardo N, Cardile V, Cicirata F (1998) Cloning of a new gap junction gene (Cx36) highly expressed in mammalian brain neurons. Eur J Neurosci 10:1202-1208.

Deans MR, Gibson JR, Sellitto C, Connors BW, Paul DL (2001) Synchronous activity of inhibitory networks in neocortex requires electrical synapses containing connexin36. Neuron 31:477-485.

Del Rio JA, de Lecea L, Ferre I, Soriano E (1994) The development of parvalbumin-immunoreactivity in the neocortex of the mouse. Brain Res Dev Brain Res 81:247-259.

Fagiolini M, Hensch TK (2000) Inhibitory threshold for critical-period activation in primary visual cortex. Nature 404:183-186.

Feng G, Mellor RH, Bernstein M, Keller-Peck C, Nguyen QT, Wallace M, Nerbonne JM, Lichtman JW, Sanes J (2000) Imaging neuronal subsets in transgenic mice expressing spectral variants of GFP. Neuron 28:41-51.

Freund TF, Buzsaki G (1996) Interneurons of the hippocampus. Hippocampus $6: 347-470$.

Fukuda T, Kosaka T (2000) Gap junctions linking the dendritic network of GABAergic interneurons in the hippocampus. $\mathbf{J}$ Neurosci 20:1519-1528.

Galarreta M, Hestrin S (1999) A network of fast-spiking cells in the neocortex connected by electrical synapses. Nature 402:72-75.

Gibson JR, Beierlein M, Connors B (1999) Two networks of electrically coupled inhibitory neurons in neocortex. Nature 402:75-79.

Gordon JA, Stryker MP (1996) Experience-dependent plasticity of binocular responses in the primary visual cortex of the mouse. $\mathrm{J}$ Neurosci 16:3274-3286.

Gray CM, Singer W (1989) Stimulus-specific neuronal oscillations in orientation columns of cat visual cortex. Proc Natl Acad Sci USA 86:1698-1702.

Gulisano M, Parenti R, Spinella F, Cicirata F (2000) Cx36 is dynamically expressed during early development of mouse brain and nervous system. NeuroReport 11:3823-3828.

Gupta A, Wang Y, Markram H (2000) Organizing principles for a diversity of GABAergic interneurons and synapses in the neocortex. Science 287:273-278.

Halasy K, Buhl EH, Lorinczi Z, Tamas G, Somogyi P (1996) Synaptic target selectivity and input of GABAergic basket and bistratified interneurons in the CA1 area of the rat hippocampus. Hippocampus $6: 306-329$

Heintz N (2000) Analysis of mammalian central nervous system gene expression and function using bacterial artificial chromosome-mediated transgenesis. Hum Mol Genet 9:143-147.

Heintz N (2001) BAC to the future: the use of transgenic mice for neuroscience research. Nat Rev Neurosci 2:861-870.

Hormuzdi SG, Pais I, LeBeau FE, Towers SK, Rozov A, Buhl EH, Whittington MA, Monyer H (2001) Impaired electrical signaling disrupts gamma frequency oscillations in connexin 36-deficient mice. Neuron 31:487-495.

Kandler K, Katz LC (1998) Coordination of neuronal activity in developing visual cortex by gap junction-mediated biochemical communication. J Neurosci 18:1419-1427.

Katsumaru H, Kosaka T, Heizmann CW, Hama K (1988) Gap junctions on GABAergic neurons containing the calcium-binding protein parvalbumin in the rat hippocampus (CA1 region). Exp Brain Res 72:363-370.

Kawaguchi Y, Kubota Y (1997) GABAergic cell subtypes and their synaptic connections in rat frontal cortex. Cereb Cortex 7:476-486.

Kawaguchi Y, Katsumaru H, Kosaka T, Heizmann CW, Hama K (1987) Fast spiking cells in the rat hippocampus (CA1 region) contain the calcium-binding protein parvalbumin. Brain Res 416:369-374.

Koh DS, Geiger JR, Jonas P, Sakmann B (1995) Ca(2+)-permeable AMPA and NMDA receptor channels in basket cells of rat hippocampal dentate gyrus. J Physiol (Lond) 485:383-402.

Koos T, Tepper JM (1999) Inhibitory control of neostriatal projection neurons by GABAergic interneurons. Nat Neurosci 2:467-472.

Kosaka T, Katsumaru H, Hama K, Wu JY, Heizmann CW (1987) GABAergic neurons containing the $\mathrm{Ca}^{2+}$-binding protein parvalbumin in the rat hippocampus and dentate gyrus. Brain Res 419:119-130.
Landisman CE, Long MA, Beierlein M, Deans MR, Paul DL, Connors BW (2002) Electrical synapses in the thalamic reticular nucleus. J Neurosci 22:1002-1009.

Maccaferri G, Roberts JD, Szucs P, Cottingham CA, Somogyi P (2000) Cell surface domain specific postsynaptic currents evoked by identified GABAergic neurones in rat hippocampus in vitro. J Physiol (Lond) 524:91-116.

Markram H, Lübke J, Frotscher M, Sakman B (1997) Regulation of synaptic efficacy by coincidence of postsynaptic APs and EPSPs. Science 275:213-215.

McBain CJ, Fisahn A (2001) Interneurons unbound. Nat Rev Neurosci 2:11-23

Miltner WH, Braun C, Arnold M, Witte H, Taub E (1999) Coherence of gamma-band EEG activity as a basis for associative learning. Nature 397:434-436

Moriyoshi K, Richards LJ, Akazawa C, O’Leary DD, Nakanishi S (1996) Labeling neural cells using adenoviral gene transfer of membranetargeted GFP. Neuron 16:255-260.

Oliva Jr AA, Jiang M, Lam T, Smith KL, Swann JW (2000) Novel hippocampal interneuronal subtypes identified using transgenic mice that express green fluorescent protein in GABAergic interneurons. J Neurosci 20:3354-3368.

Peinado A (2000) Traveling slow waves of neural activity: a novel form of network activity in developing neocortex. J Neurosci 20:RC54:1-6.

Peinado A (2001) Immature neocortical neurons exist as extensive syncitial networks linked by dendrodendritic electrical connections. J Neurophysiol 85:620-629.

Peinado A, Yuste R, Katz LC (1993) Extensive dye coupling between rat neocortical neurons during the period of circuit formation. Neuron 10:103-114.

Rodriguez E, George N, Lachaux JP, Martinerie J, Renault B, Varela FJ (1999) Perception's shadow: long-distance synchronization of human brain activity. Nature 397:430-433.

Schleef M, Zühlke C, Jokusch H, Schöffl F (1992) The structure of the mouse parvalbumin gene. Mamm Genome 3:217-225.

Sik A, Penttonen M, Ylinen A, Buzsaki G (1995) Hippocampal CA1 nterneurons: an in vivo intracellular labeling study. J Neurosci 15:6651-6665.

Singer W, Gray CM (1995) Visual feature integration and the temporal correlation hypothesis. Annu Rev Neurosci 18:555-586.

Söhl G, Degen J, Teubner B, Willecke K (1998) The murine gap junction gene connexin 36 is highly expressed in mouse retina and regulated during brain development. FEBS Lett 428:27-31.

Strata F, Atzori M, Molnar M, Ugolini G, Tempia F, Cherubini E (1997) A pacemaker current in dye-coupled hilar interneurons contributes to the generation of giant GABAergic potentials in developing hippocampus. J Neurosci 17:1435-1446.

Szabadics J, Lorincz A, Tamas G (2001) $\beta$ and $\gamma$ frequency synchronization by dendritic GABAergic synapses and gap junctions in a network of cortical interneurons. J Neurosci 21:5824-5831.

Tamas G, Buhl EH, Lorincz A, Somogyi P (2000) Proximally targeted GABAergic synapses and gap junctions synchronize cortical interneurons. Nat Neurosci 3:366-371.

Traub RD, Whittington MA, Stanford IM, Jefferys JG (1996) A mechanism for generation of long-range synchronous fast oscillations in the cortex. Nature 383:621-624.

Traub RD, Spruston N, Soltesz I, Konnerth A, Whittington MA, Jefferys JGR (1998) Gamma-frequency oscillations: a neuronal population phenomenon, regulated by synaptic and intrinsic cellular processes, and inducing synaptic plasticity. Prog Neurobiol 55:563-575.

Venance L, Rozov A, Blatow M, Burnashev N, Feldmeyer D, Monyer H (2000) Connexin expression in electrically coupled postnatal rat brain neurons. Proc Natl Acad Sci USA 97:10260-10265.

Whittington MA, Traub RD, Jefferys JGR (1995) Synchronized oscillations in interneuron networks driven by metabotropic glutamate receptor activation. Nature 373:612-615.

Yang XW, Model P, Heintz N (1997) Homologous recombination based modification in Escherichia coli and germline transmission in transgenic mice of a bacterial artificial chromosome. Nat Biotechnol 15:859-865.

Ylinen A, Bragin A, Nadasdy Z, Jando G, Szabo I, Sik A, Buzsaki G (1995) Sharp wave-associated high-frequency oscillation $(200 \mathrm{~Hz})$ in the intact hippocampus: network and intracellular mechanisms. J Neurosci 15:30-46.

Yuste R, Peinado A, Katz LC (1992) Neuronal domains in developing neocortex. Science 257:665-669.

Yuste R, Nelson DA, Rubin WW, Katz LC (1995) Neuronal domains in developing neocortex: mechanisms of coactivation. Neuron 14:7-17.

Zuo J, Treadaway J, Buckner TW, Fritzsch B (1999) Visualization of $\alpha 9$ acetylcholine receptor expression in hair cells of transgenic mice containing a modified bacterial artificial chromosome. Proc Natl Acad Sci USA 96:14100-14105. 